\title{
Study of Optimization of Recycle Coarse Aggregate on Strength Characteristics of Different Grades of Structural Concrete
}

\author{
Er. Nirmaljeet ${ }^{1}$, Er. Vikram ${ }^{2}$ \\ Research Fellow (M. Tech), Civil Department, Jan Nayak Ch. Devilal Memorial College of Engineering Sirsa, India ${ }^{1}$ \\ Assistant Professor, Civil Department, Jan Nayak Ch. Devilal Memorial College of Engineering, Sirsa, India ${ }^{2}$
}

\begin{abstract}
A study based upon the analysis of the various experimental results for the fresh and hardened stage of the different concrete mix with different replacement levels of natural coarse aggregate with recycle coarse aggregates is presented in the paper. The recycled coarse aggregate were obtained from mobile crusher plant located in Sangrur (Punjab). The crushed aggregate was that of M30 grade demolished bridge deck slab and pier.Three types of concrete mixture were selected for a testing, i.e. M25, M30 \&M35grade. The first two mixtures i.e(M25 \&M30)are somewhat same as that of parent concrete (M30) from which recycled coarse aggregate is derived, so they were selected as $1^{\text {st }}$ series where as $3^{\text {rd }}$ mixture M35 was selected as $2^{\text {nd }}$ series. For the first series, concrete was made entirely with natural aggregate as a control specimen and concrete was made with recycle coarse aggregate with $50 \& 100 \%$ replacement levels of natural coarse aggregate. For $2^{\text {nd }}$ series, concrete was made entirely with natural coarse aggregate as control specimen and two types of concrete with fly ash (15\% and $25 \%$ replacement of cement) and recycle coarse aggregate (50\% and $100 \%$ replacement of natural coarse aggregate) were made. 72 cube specimen and 36 beam specimens were made for testing of basic properties (cubes for compressive strength and split tensile strength; beam specimen for flexural strength) of hardened concrete. The fresh property i.e, the slump value for each investigated concrete type is also presented in the paper. In $1^{\text {st }}$ series (M25 \&M30), recycled aggregate concrete did not diverge its properties as compared with the control specimen, regardless of the replacement ratio by recycled aggregates. However for the $2^{\text {nd }}$ series (M35), in order to achieve the desired strength, fly ash was used as the replacement of cement. The test results obtained were somewhat more than that of control sample.
\end{abstract}

Keyword: recycle coarse aggregate, natural coarse aggregate, fly ash, structural concrete.

\section{INTRODUCTION}

In today's world, the "change" is the frequent phenomenon especially related to the infrastructural development. The old and worn out buildings and traffic related structures which have passed their prime are demolished. The new structures take their place in order to meet the present requirement. This is quite a frequent phenomenon today in a large part of the world. These changes may be associated with various reasons like changes of purpose, structural deterioration, rearrangement of a city, expansion of traffic directions and increasing traffic load, natural disasters (earthquake, fire and flood), etc. a large amount of solid waste is generated which is mostly managed by disposing it in the landfill purposes. The quantity of construction waste created is quite large, thus posing a huge problem of human environment pollution. For the above mentioned reason, many developed countries have passed strict laws to minimise this waste generation. The laws may be in the form of prohibitions or special taxes existing for creating waste areas.

If we flip the other side of the coin, the need for the production and consumption of specific grade concrete is continuously increasing. This all rapidly increasing phenomenon of concrete requirement leads to the increased consumption of natural aggregate, which is the largest concrete component. In order to deal with the climatic degradation due to concrete, stress has been laid upon the preservation of natural aggregates sources. Heavy taxes have been imposed upon the use of virgin aggregates in order to discourage its use in many European countries. Many other possible alternatives have been continually searched. A possible solution to these problems is to recycle demolished concrete and use it as a component of new structural concrete in the form of coarse aggregate or fine aggregate.

Recycled concrete aggregate (RCA) is generally produced by two-stage crushing of demolished concrete, and screening and removal of contaminants such as reinforcement, paper, wood, plastics and gypsum. Concrete made with such recycled concrete aggregate is called recycled aggregate concrete (RAC). The process of producing recycled aggregates is that once concrete rubble has been deposited at a recycling plant, it is then broken by a pulveriser mounted on a excavator. Pieces of concrete waste broken to a suitable size are then crushed in a primary jaw crusher and then passed via conveyor belts into a cone crusher. The crushed material is passed through a set of vibrating 
screens and sieved on the way to a stock pile. After each crusher, the rotating magnets remove remains of steel reinforcement where as pickers manually remove other contaminants.

The main purpose of this work is to study the optimum use of recycled aggregate by determining the basic properties of RAC depending on the coarse recycled aggregate content, and to compare them to the properties of concrete made with natural aggregate (NAC) - control concrete. Fine recycled aggregate was not considered for RAC production because its application in structural concrete is generally not recommended.

\section{EXPERIMENTAL INVESTIGATION}

The aim of this investigation is to compare the basic properties of control concrete (concrete made with natural aggregate) and the properties of concrete made with different contents of recycled aggregate. For this purpose, Three types of concrete mixture were selected for a testing, i.e. M25, M30 \&M35grade. The first two mixtures i.e. (M25 \&M30) are somewhat same as that of parent concrete (M30) from which recycled coarse aggregate is derived, so they were selected as $1^{\text {st }}$ series where as $3^{\text {rd }}$ mixture M35 was selected as $2^{\text {nd }}$ series.

The type and quantity of coarse aggregate were varied in the following way:

- the first concrete mix series (M25 and M30), concrete was made entirely with natural aggregate as a control specimen and concrete was made with recycle coarse aggregate with $50 \& 100 \%$ replacement levels of natural coarse aggregate.

- the second concrete mix series, concrete was made entirely with natural coarse aggregate as control specimen and two types of concrete with fly ash (15\% and 25\% replacement of cement) and recycle coarse aggregate (50\% and $100 \%$ replacement of natural coarse aggregate).

72 cube specimen and 36 beam specimens were made for testing of basic properties (cubes for compressive strength and split tensile strength; beam specimen for flexural strength) of hardened concrete.

The experimental work layout diagran has been shown below in figure 1:

\section{EXPERIMENTAL WORK LAYOUT DIAGRAM}

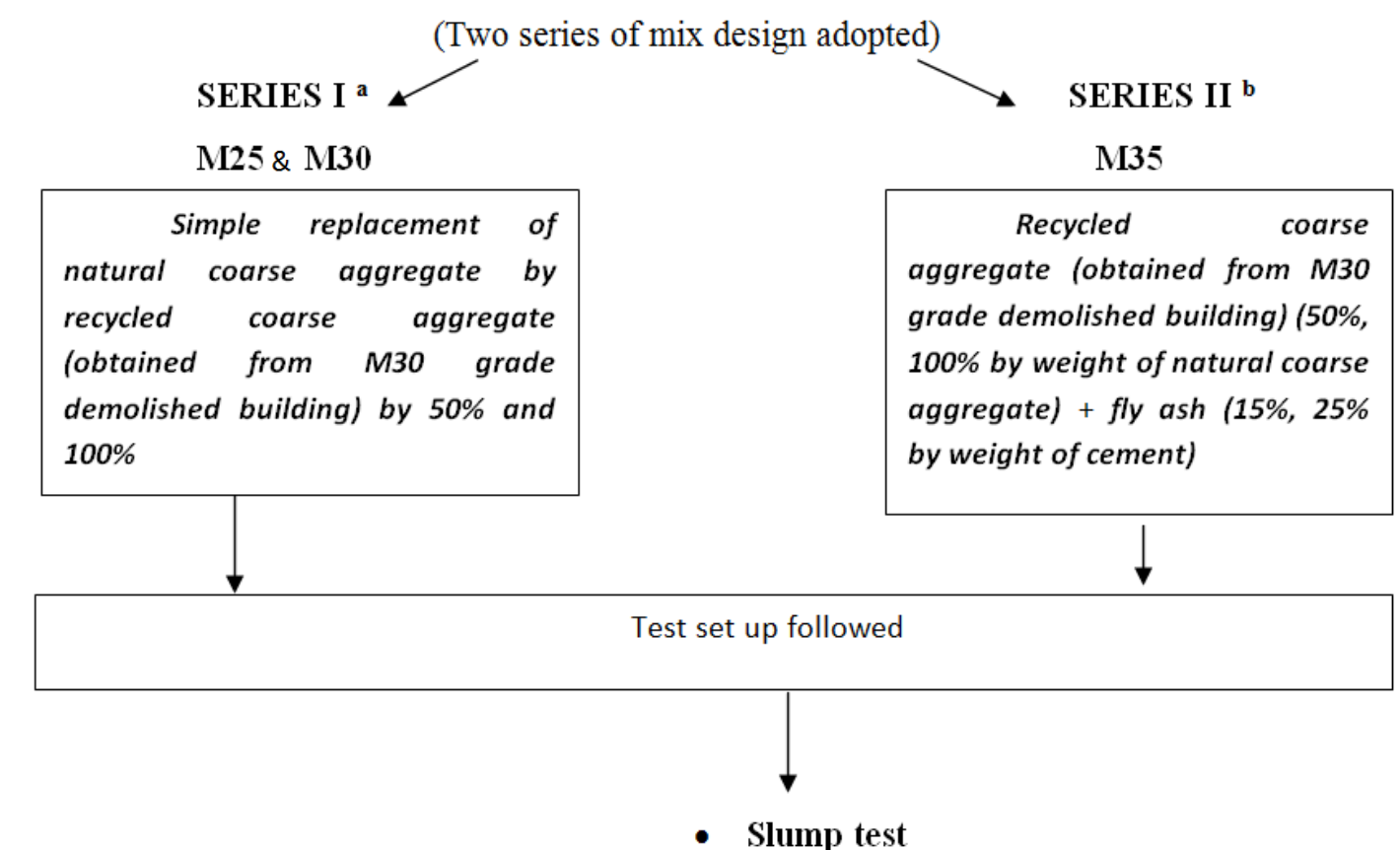

- Compressive strength test

- Split tensile strength

- Flexure test

a. Component materials:

Figure 1. experimental work layout programme

Component material for the concrete mixtures were:

$\rightarrow$ Ordinary Portland cement of grade - 43 (J.K cement) conforming to Indian standard IS: 8112-1989 has been used in the present study. 
$\rightarrow$ Standard sand confirming to grading zone III was used as fine aggregate.

$\rightarrow$ Locally available coarse aggregate having the maximum size of $20 \mathrm{~mm}$ was used as coarse aggregate in the research work.

$\rightarrow$ Class F fly ash was procured from Guru Nanak Dev Thermal Plant (GNDTP), Bathinda, Punjab having specific gravity as 2.31 and satisfying IS 3812-1999.

$\rightarrow$ Recycle coarse aggregate were taken from mobile crusher unit located in Sangrur (Punjab). The larger fraction, passing through $20 \mathrm{~mm}$ sieve but retained on $12.5 \mathrm{~mm}$ sieve was designated RCA20 - $12.5 \mathrm{~mm}$. The fraction passing through $12.75 \mathrm{~mm}$ sieve was discarded.

All component materials were tested prior to mix proportion design. The results of natural aggregate testing are shown in Table 1

Table 1 Physical properties of natural and recycled coarse aggregate

\begin{tabular}{|l|l|l|l|}
\hline S. No. & Properties & Natural aggregates & Recycled aggregates \\
\hline 1. & Specific gravity & 2.67 & 2.31 \\
\hline 2. & Water absorption $(\%)$ & 1.8 & 6.2 \\
\hline 3. & Fineness modulus $(\%)$ & 7.6 & 7.8 \\
\hline 4. & Aggregate impact value $(\%)$ & 12.82 & 35.41 \\
\hline 5. & Aggregate crushing value $(\%)$ & 15.31 & 24.87 \\
\hline
\end{tabular}

\section{b. Mix Combinations}

The recycled aggregate collected from crushing plant was of a bridge pillar whose design strength was M30. Since we knew of the parent concrete strength, it was decided to design two mix proportions series for further testing. Mix design was done in according to IS-10262. All the necessary tests were carried out on all the constituent materials to design the proper mix. The mix design is given in table 2 below:

Table 2: Mix Proportion of Control Sample

\begin{tabular}{|c|c|c|c|c|c|}
\hline Series & $\begin{array}{c}\text { Designation/ mix design } \\
\text { grade }\end{array}$ & $\begin{array}{c}\text { WATER } \\
\left(\mathbf{K g} / \mathbf{m}^{\mathbf{3}}\right)\end{array}$ & $\begin{array}{c}\mathbf{C E M E N T} \\
\left(\mathbf{K g} / \mathbf{m}^{\mathbf{3}}\right)\end{array}$ & $\begin{array}{c}\text { SAND } \\
\left(\mathbf{K g} / \mathbf{m}^{\mathbf{3}}\right)\end{array}$ & $\begin{array}{c}\mathbf{C . A .} \\
\left(\mathbf{K g} / \mathbf{m}^{\mathbf{3}}\right)\end{array}$ \\
\hline \multirow{2}{*}{$\mathrm{I}$} & $\mathrm{M} 25$ & 200.71 & 404 & 671 & 1147 \\
\cline { 2 - 6 } & $\mathrm{M} 30$ & 200.66 & 413 & 672 & 1139 \\
\hline $\mathrm{II}$ & $\mathrm{M} 35$ & 200.30 & 365 & 673 & 1094 \\
\hline
\end{tabular}

For M25 and M30 grade, it was simple replacement of natural coarse aggregate by recycled coarse aggregate. But, for M35, not only coarse aggregate was replaced but cement was also replcaed by fly ash.

Table 3 gives the proportion of different constituents in the mix.

Table 3: Mix Proportions And Notations For Different Samples (For $1 \mathbf{~ m}^{3}$ )

\begin{tabular}{|c|c|c|c|c|c|c|c|c|c|}
\hline Series & Designation & $\begin{array}{c}\text { FA } \\
\%\end{array}$ & $\begin{array}{c}\text { RA } \\
\%\end{array}$ & $\begin{array}{c}\text { Water } \\
\text { (kg) }\end{array}$ & $\begin{array}{c}\text { Cement } \\
(\mathrm{kg})\end{array}$ & $\begin{array}{l}\text { F.A.(fly } \\
\text { ash)(kg) }\end{array}$ & $\begin{array}{c}\text { Sand } \\
\text { (kg) }\end{array}$ & $\begin{array}{l}\text { C.A. } \\
\text { (kg) }\end{array}$ & $\begin{array}{r}\text { R.A. } \\
\text { (kg) }\end{array}$ \\
\hline \multirow{6}{*}{ I } & M25RA0 & 0 & 0 & 200.71 & 404 & 0 & 671 & 1147 & 0 \\
\hline & M25RA50 & 0 & 50 & 200.71 & 404 & 0 & 671 & 573.5 & 573.5 \\
\hline & M25RA100 & 0 & 100 & 200.71 & 404 & 0 & 671 & 0 & 1147 \\
\hline & M30RA0 & 0 & 0 & 200.66 & 413 & 0 & 672 & 1139 & 0 \\
\hline & M30RA50 & 0 & 50 & 200.66 & 413 & 0 & 672 & 570 & 569 \\
\hline & M30RA100 & 0 & 100 & 200.66 & 413 & 0 & 672 & 0 & 1139 \\
\hline \multirow{8}{*}{ II } & M35RA0 & 0 & 0 & 200.3 & 465 & 0 & 673 & 1094 & 0 \\
\hline & M35RA50 & 0 & 50 & 200.3 & 465 & 0 & 673 & 547 & 547 \\
\hline & M35RA100 & 0 & 100 & 200.3 & 465 & 0 & 673 & 0 & 1094 \\
\hline & M35RA0 FA 15 & 15 & 0 & 200.3 & 465 & 69.75 & 673 & 1094 & 0 \\
\hline & M35RA50FA15 & 15 & 50 & 200.3 & 465 & 69.75 & 673 & 547 & 547 \\
\hline & M35RA100FA15 & 15 & 100 & 200.3 & 465 & 69.75 & 673 & 0 & 1094 \\
\hline & M35RA0FA25 & 25 & 0 & 200.3 & 465 & 116.25 & 673 & 1094 & 0 \\
\hline & M35RA50FA25 & 15 & 50 & 200.3 & 465 & 116.25 & 673 & 547 & 547 \\
\hline
\end{tabular}




\begin{tabular}{|l|l|l|l|l|l|l|l|l|}
\hline M35RA100FA25 & 15 & 100 & 200.3 & 465 & 116.25 & 673 & 0 & 1094 \\
\hline
\end{tabular}

\section{RESULT AND ANALYSIS}

\section{Properties of Fresh Concrete}

Slump test is the most common method to determine the consistence of fresh concrete. The details of the mix proportioning for various mixes of both normal and recycled aggregate concrete made with different percentages of Recycled Coarse Aggregate are presented in Table 4

Table 4: Slump values for various design mix

\begin{tabular}{|c|c|c|}
\hline Series & Designation & Slump (mm) \\
\hline \multirow{4}{*}{ I } & $\mathrm{M}_{25}$ RA0 & 96 \\
\cline { 2 - 3 } & $\mathrm{M}_{25}$ RA50 & 110 \\
\cline { 2 - 3 } & $\mathrm{M}_{25}$ RA100 & 118 \\
\cline { 2 - 3 } & $\mathrm{M}_{30}$ RA0 & 91 \\
\cline { 2 - 3 } & $\mathrm{M}_{30}$ RA50 & 104 \\
\cline { 2 - 3 } & $\mathrm{M}_{30}$ RA100 & 123 \\
\hline \multirow{4}{*}{ II } & $\mathrm{M}_{35}$ RA0 & 80 \\
\cline { 2 - 3 } & $\mathrm{M}_{35}$ RA50 & 92 \\
\cline { 2 - 3 } & $\mathrm{M}_{35}$ RA100 & 102 \\
\cline { 2 - 3 } & $\mathrm{M}_{35}$ RA0 FA 15 & 89 \\
\cline { 2 - 3 } & $\mathrm{M}_{35}$ RA50FA15 & 103 \\
\cline { 2 - 3 } & $\mathrm{M}_{35}$ RA100FA15 & 114 \\
\cline { 2 - 3 } & $\mathrm{M}_{5}$ RA20FA25 & 98 \\
\cline { 2 - 3 } & $\mathrm{M}_{35}$ RA50FA25 & 112 \\
\cline { 2 - 3 } & $\mathrm{M}_{35}$ RA100FA25 & 131 \\
\hline
\end{tabular}

It is observed that in all the mixes the workability decreases with increase in recycled coarse aggregate percentage. This may due to the high absorption capacity and rough surface texture of Recycled Coarse Aggregates.

\section{Compressive Strength Test}

The compressive strength of concrete was determined using a compression machine at the ages of 7 and 28 days.

Table 5: Compressive strength of specimen at 7 and 28 days

\begin{tabular}{|c|c|c|c|}
\hline \multirow{2}{*}{ Series } & \multirow{2}{*}{ Designation } & \multicolumn{2}{|c|}{ COMPRESSIVE STRENGTH (Mpa) } \\
\hline & & 7 Day $F_{c k}$ & 28 Day $F_{\mathrm{ck}}$ \\
\hline \multirow{6}{*}{ I } & $\mathrm{M}_{25} \mathrm{RA} 0$ & 20.12 & 32.45 \\
\hline & $\mathrm{M}_{25}$ RA50 & 22.14 & 33.31 \\
\hline & $\mathrm{M}_{25} \mathrm{RA} 100$ & 22.36 & 35.11 \\
\hline & $\mathrm{M}_{30} \mathrm{RA} 0$ & 25.64 & 39.54 \\
\hline & $\mathrm{M}_{30}$ RA50 & 26.12 & 39.05 \\
\hline & $\mathrm{M}_{30} \mathrm{RA} 100$ & 25.32 & 38.85 \\
\hline \multirow{9}{*}{ II } & $\mathrm{M}_{35} \mathrm{RA} 0$ & 27.85 & 42.87 \\
\hline & $\mathrm{M}_{35}$ RA50 & 25.46 & 38.91 \\
\hline & $\mathrm{M}_{35}$ RA100 & 23.44 & 36.24 \\
\hline & $\mathrm{M}_{35}$ RA0 FA 15 & 26.74 & 44.03 \\
\hline & $\mathrm{M}_{35} \mathrm{RA} 50 \mathrm{FA} 15$ & 27.82 & 43.59 \\
\hline & $\mathrm{M}_{35}$ RA100FA15 & 28.53 & 42.93 \\
\hline & M35RA0FA25 & 25.41 & 43.25 \\
\hline & $\mathrm{M}_{35} \mathrm{RA} 50 \mathrm{FA} 25$ & 29.12 & 43.78 \\
\hline & $\mathrm{M}_{35}$ RA100FA25 & 31.45 & 45.87 \\
\hline
\end{tabular}

For series I, there is increase in strength with the increase in recycled coarse aggregates. The main reason is that the adhered cement paste on the recycled aggregate is that of M30 grade concrete. 
When this recycled aggregate, is used for lower grade M25 concrete, there is increase in strength. The old film of adhered cement mortar phase leads to formation of even stronger, newer inter transitional zone of new concrete.

Fir series II, there is decrease in strength of concrete mix with the increase in content of recycled coarse aggregates. The reason is that due to the presence of old cement mortar film hinders the formation of new inter transitional zone leading to decrease strength of concrete mix.

In order to increase in the strength for series II, fly ash was added. It is clear from the above discussion that with the addition of fly ash, the value of compressive strength increases with increase in replacement level of cement by fly ash. This is due to the reason that fly ash particles are finer, spherical which means that they have high specific area which leads to good pozzolanic action. Thus a strong new intertransitional phase forms leading to high strength.

Flexural Strength Test and Split Tensile Strength

Flexural strength and split tensile strength studies were carried out at the age of 28 days as shown in table

Table 6: Flexural Strength Test and Split Tensile Strength Test of Specimens

\begin{tabular}{|c|c|c|c|}
\hline \multirow{3}{*}{ Series } & \multirow{2}{*}{ Designation } & Flexural strength (Mpa) & Split Tensile strength (Mpa) \\
\cline { 2 - 4 } & & 28 DAY & 28 DAY \\
\hline \multirow{4}{*}{ I } & $\mathrm{M}_{25}$ RA0 & 4.35 & 3.12 \\
\cline { 2 - 4 } & $\mathrm{M}_{25}$ RA50 & 4.57 & 3.34 \\
\cline { 2 - 4 } & $\mathrm{M}_{25}$ RA100 & 4.77 & 3.54 \\
\cline { 2 - 4 } & $\mathrm{M}_{30}$ RA0 & 4.49 & 3.37 \\
\cline { 2 - 4 } & $\mathrm{M}_{30}$ RA50 & 4.58 & 3.49 \\
\hline \multirow{4}{*}{ II } & $\mathrm{M}_{30}$ RA100 & 4.61 & 3.41 \\
\cline { 2 - 4 } & $\mathrm{M}_{35}$ RA0 & 4.75 & 3.52 \\
\cline { 2 - 4 } & $\mathrm{M}_{35}$ RA50 & 4.51 & 3.28 \\
\cline { 2 - 4 } & $\mathrm{M}_{35}$ RA100 & 4.26 & 3.03 \\
\cline { 2 - 4 } & $\mathrm{M}_{35}$ RA0 FA 15 & 5.01 & 3.78 \\
\cline { 2 - 4 } & $\mathrm{M}_{35}$ RA50FA15 & 5.08 & 3.85 \\
\cline { 2 - 4 } & $\mathrm{M}_{35}$ RA100FA15 & 5.12 & 3.89 \\
\cline { 2 - 4 } & $\mathrm{M}_{3}$ 3RA0FA25 & 5.04 & 3.81 \\
\cline { 2 - 4 } & $\mathrm{M}_{35}$ RA50FA25 & 5.25 & 4.02 \\
\cline { 2 - 4 } & $\mathrm{M}_{35}$ RA100FA25 & 5.36 & 4.13 \\
\hline
\end{tabular}

The variation in split tensile strength and flexural strength is same as the behaviour shown in compressive strength for series I and series II.

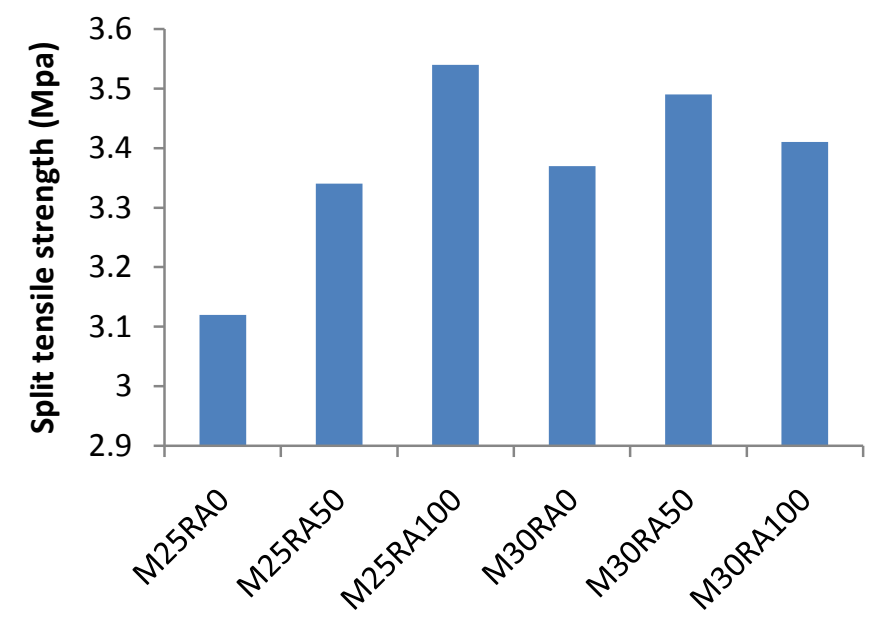

Figure 2: Split tensile strength of series I at 28 days

For series $\mathbf{1}^{\text {st }}$ the value of split tensile strength increases with the increase in recycled coarse aggregates. The main reason is that the adhered cement paste on the recycled aggregate is that of M30 grade concrete. When this recycled 
aggregate, is used for lower grade M25 concrete, there is increase in strength. The old film of adhered cement mortar phase leads to formation of even stronger, newer inter transitional zone of new concrete.

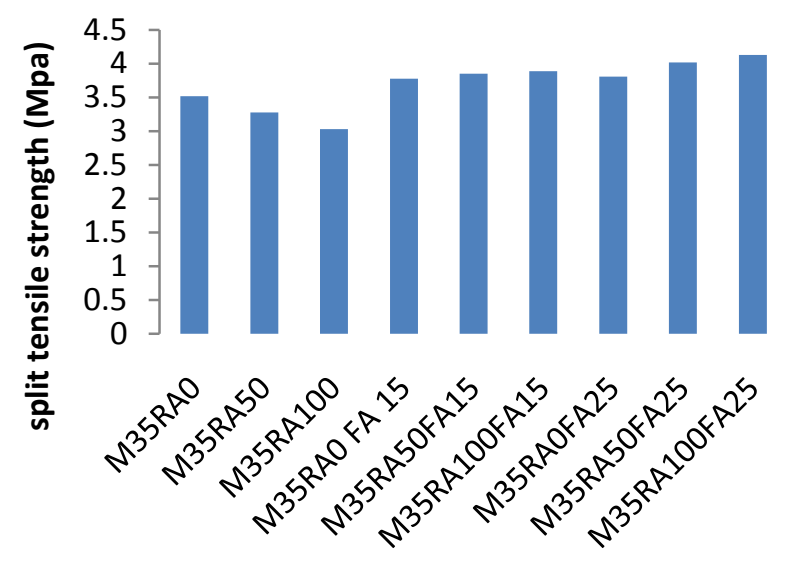

Figure 3: Split tensile strength of series II at 28 days

For series $2^{\text {nd }} \mathbf{M} 35$ there was decrease in strength with increase in replacement level of recycled coarse aggregate. The reason is that due to the presence of old cement mortar film hinders the formation of new inter transitional zone leading to decrease strength of concrete mix.

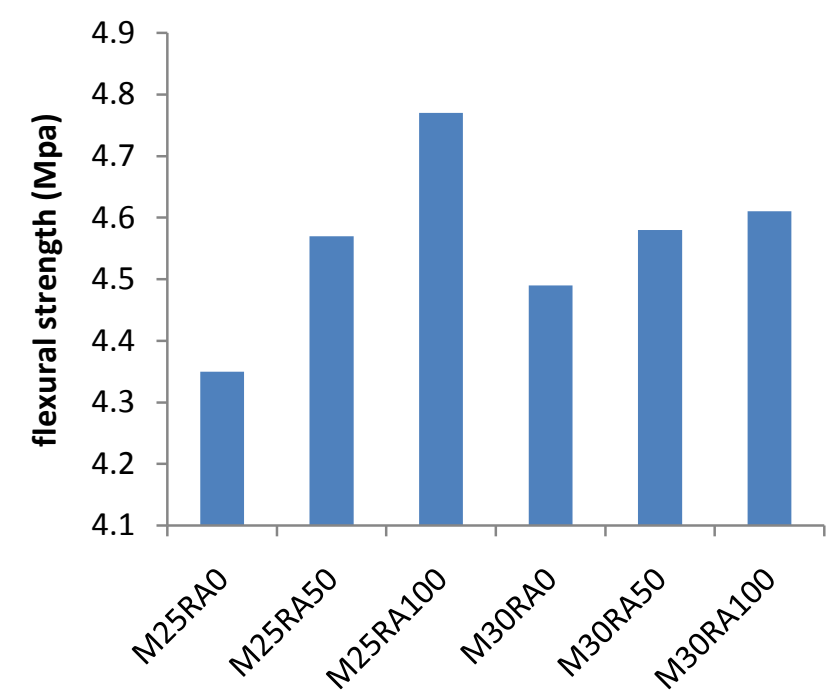

Figure 4: Flexural strength of series I at 28 days 


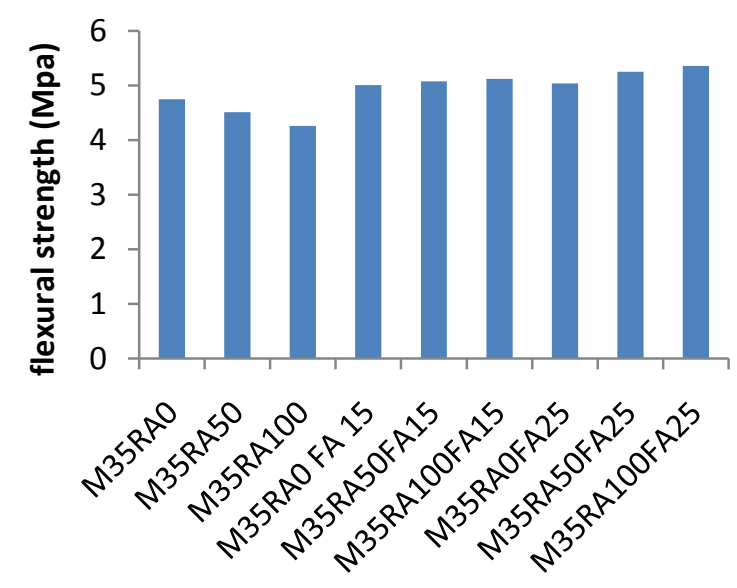

Figure 5: Flexural strength of series II at 28 days

In order to increase in the strength for series II, fly ash was added. It is clear from the above discussion that with the addition of fly ash, the value of compressive strength increases with increase in replacement level of cement by fly ash. This is due to the reason that fly ash particles are finer, spherical which means that they have high specific area which leads to good pozzolanic action. Thus a strong new intertransitional phase forms leading to high strength.

THE behaviour of flexure strenght is same as split \&compressive strenght at $1^{\text {st }} \& 2^{\text {nd }}$ series.

\section{CONCLUSIONS}

Experimental works on the use of recycled aggregates without fly ash for lower grade concrete and with the fly ash for higher grade on RAC have proven that good quality concrete could be produced with recycled aggregates. The use of aggregates produced from recycled construction and demolition waste should be further promoted. Based on the experimental investigation reported in the work, the following conclusions are drawn.

- If we increase the content of recycle coarse aggregate, the workability tends to increase

- If we add supplementary materials like fly ash to the concrete mix, then also workability increases.

- If we know the origin of recycled coarse aggregate, it significantly affects the desired strength of the new mix.

- Recycled coarse aggregate derived from higher strength parent concrete grade can be used to obtain lower strength concrete mix.

- Recycled coarse aggregate derived from lower strength parent concrete grade cannot be used to obtain higher strength concrete mix.

- Supplementary materials like fly ash can be incorporated to obtain higher strength recycled aggregate concrete.

- The tensile strength and flexural strength of the mix is significantly affected by the origin of the recycled coarse aggregate.

- At $100 \%$ replacement level of natural coarse aggregate by recycled coarse aggregate in M25 maximum strenght is achieved.

- In M30 at 50\% replacement level of natural coarse aggregate by recycled coarse aggregate maximum strenght is achieved.

- In M35 grade at $100 \%$ replacement level of natural coarse aggregate by recycled aggregate and cement replacement with fly ash at $25 \%$ maximum strenght is achieved.

\section{REFERENCES}

[1] Andreu G., Miren E. (2014). "Experimental analysis of properties of high performance recycled aggregate concrete.” Construction and Building Materials Vol. 52 pp 227-235.

[2] Butler L., West J.S., Tighe S.L. (2013). "Effect of recycled concrete coarse aggregate from multiple sources on the hardened properties of concrete with equivalent compressive strength." Construction and Building Materials Vol. 47 pp 1292-1301.

[3] Corinaldesi V., Moriconi G. (2009). "Influence of mineral additions on the performance of 100\% recycled aggregate concrete." Construction and Building Materials Vol. 23 pp 2869-2876.

[4] Carneiro J.A., Lima P.R.L., Monica B.L., Filho R.D.T. (2014). “Compressive stress strain behavior of steel fiber reinforced-recycled aggregate concrete." Cement and Concrete Composites Vol. 46 pp 65-72.

[5] Dilbas H., Simsek M., Cakir O. (2014). "An investigation on mechanical and physical properties of recycled aggregate concrete (RAC) with and without silica fume." Construction and Building Materials Vol. 61 pp 50-59.

[6] Duan Z.H., Poon C.S. (2014). "Properties of recycled aggregate concrete made with recycled aggregates with different amounts of old adhered mortars." Materials and Design Vol. 58 pp 19-29. 
[7] Hemlatha B.R., Prasad N., Subramanya B.V.V. (2008). "Construction and demolition waste recycling for sustainable growth and development." Journal of Environmental Research and Development Vol. 2

[8] Gayarre F.L., Perez C.L.C., Lopez M.A.S., Cabo A.D. (2014). "The effect of curing conditions on the compressive strength of recycled aggregate concrete." Construction and Building Materials Vol. 53 pp 260-266.

[9] IS: 10262-1982 (Reaffirmed 2004): Recommended guidelines for concrete mix design, Bureau of Indian Standard, New Delhi-2004. 